\title{
UMA UTILIZAÇÃO DE PARÂMENTROS ERGONÔMICOS DE PROJETOS PARA CONFIGURAR O ESPAÇO DE TRABALHO EM ESCRITÓRIO
}

\author{
COSTA, Ana Paula Lima \\ Ministério da Fazenda, Doutora em Design \\ e-mail:aplimacosta@gmail.com
}

\begin{abstract}
RESUMO
Este artigo é parte de uma tese de doutorado, descrevendo a metodologia de planejamento de espaço de trabalho fundamentada em princípios ergonômicos, desenvolvida a partir da adaptação do método Hipotético-Dedutivo, que resultou em um processo de configuração de espaço de trabalho em ambiente construído de escritório. A aplicação possibilitou formatar os postos de trabalho para exercer as atividades, dimensionar os espaços físicos e elencar a tipologia dos espaços de trabalho para suprir as expectativas da política administrativa da empresa. Um Modelo de Configuração sintetizou os procedimentos adotados na metodologia, adaptando-os a um processo de configuração de postos de trabalho.
\end{abstract}

Palavras chave: metodologia de projeto, projeto do espaço de trabalho, planejamento de escritório.

\begin{abstract}
This article is part of a doctoral thesis, describing a methodology of planning workspace based on ergonomic principles, developed from the adaptation of the Hypothetical-Deductive method, which resulted in a process of configuration of work space in an office environment. The application made it possible to format the workstations to carry out the activities, design the physical spaces and list the typology of the workspaces to meet the expectations of the company's administrative policy. A Configuration Model synthesized the procedures adopted in the methodology, adapting them to a process of job configuration.
\end{abstract}

Keywords: project methodology, workspace design, office planning

\section{INTRODUÇÃO}

Esse estudo é parte de uma tese de doutorado desenvolvida pela autora.

As metodologias de projetos de ambientes construídos planejam racionalmente e impõem padrões de espaço que, muitas vezes, não coincidem com os padrões culturais das pessoas. Tendo em vista que, para se propor um modelo de ocupação física deve-se identificar as atitudes comportamentais, o trabalho e tarefas a realizar e suas influências dentro do ambiente, faz-se necessário levar em consideração as necessidades daqueles que irão utilizar o ambiente. Assim, a ergonomia, disciplina científica que atua de forma sistemática utilizando-se de instrumentos provenientes da ciência e da tecnologia, e que tem como foco o homem em situação real de trabalho, torna-se uma importante ferramenta de auxílio para a compreensão do ambiente construído e sua influência sobre o usuário. 


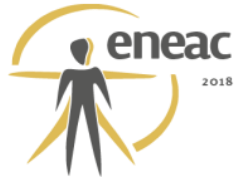

\section{O PROCESSO DE PROJETO}

Tomando-se os processos de projeto de ambientes construídos como referência de concepção de espaço, verifica-se que, para garantir as condições de usabilidade e funcionalidade dos ambientes de trabalho, a determinação do espaço para realizar as atividades é feita a partir do conhecimento das aspirações do usuário. A partir desse conhecimento, são estipulados quantidades e formatos de espaço que estimam como os usuários interagirão com o ambiente (IAB, 2013).

Partindo do pressuposto de que um ambiente de trabalho seja composto por um conjunto de postos de trabalho, a quantificação e a configuração desse ambiente deveriam ser baseadas pelo conjunto de necessidades dos indivíduos que utilizam o espaço dos seus postos de trabalho. Portanto, sem investigação sobre os hábitos dos usuários, os projetistas não teriam como fundamentar os seus parâmetros de concepção.

Apesar de haverem publicações que norteiam a quantificação do espaço necessário para exercer as atividades (NEUFERT 2013; BOUERI, 2008; PANERO e ZELNIK, 2008), o auxílio de uma ferramenta que introduzisse o uso de fatores ergonômicos nos projetos contribuiria para identificar elementos essenciais da atividade humana, conduzindo o projeto para que atenda aos anseios dos usuários e projetistas envolvidos no processo. Contudo, devido à multidisciplinaridade da atividade projetual, faz-se necessário sistematizar as ferramentas utilizadas para conhecer as atividades dos usuários com os procedimentos de quantificação do espaço de trabalho.

\section{O ESPAÇO DE ESCRITÓRIO}

O escritório existe para que uma empresa realize os seus propósitos com eficiência e efetividade. A decisão sobre o arranjo físico de um escritório está relacionada com a cultura organizacional e a necessidade funcional.

De acordo com o processo de projeto, o dimensionamento do espaço de trabalho segue as diretrizes contidas no programa de necessidades, em que o usuário descreve as características necessárias para operar no seu local de trabalho com conforto e segurança. Por conseguinte, os projetos de ambientes necessitam de referências em aspectos específicos voltados a uma adequação entre o corpo humano e os vários componentes dos espaços interiores, baseados em dados antropométricos fundamentados.

As publicações técnicas e normas regulamentadoras se debruçam em fornecer dados para balizar a forma e a dimensão das mesas de escritório, indicando as larguras, profundidades e espaços de movimentação no posto de trabalho. Intencionando prover a comunidade de projetistas com referências dimensionais que possibilitem a elaboração de projetos de ambientes de escritório, pesquisadores sugerem áreas de ocupação a serem destinadas a cada trabalhador seguindo padrões hierárquicos e funcionais (MEEL et al. , 2010; MARMOT, ELEY, 2000; CURY, 2005; PILE, 1984; BRILL et al., 1984; HARRIS et al., 1981; CHARLES et al., 2004). Baseados no conceito de que cada indivíduo tem um local de trabalho, os autores pontuam que espaços com medidas padrões definem o quanto de área de um prédio deve ser dado para cada pessoa, estimando o tamanho que a empresa deverá ter. Encontram-se, também, publicações cujos autores concentraram-se nos aspectos antropométricos da ergonomia e organizaram os dados para serem aplicados no projeto de espaços anteriores (BOUERI FILHO, 2007; NEUFERT, 2013; PANERO, ZELNIK, 2008). O dimensionamento do espaço também é guiado por normas técnicas que padronizam medidas antropométricas a serem utilizadas nos mobiliários de escritório (ABNT, 2015). 


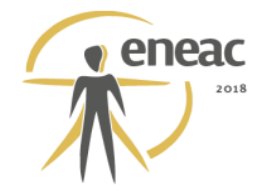

\section{METODOLOGIA}

Tendo em vista a intenção de estruturar uma metodologia de concepção de espaço que resulte em um roteiro de atividades projetuais, optou-se pela adaptação do método cientifico Hipotético-dedutivo (MARCONI, LAKATOS, 2003) para que, partindo de um conflito entre teorias existentes, chegasse-se a uma nova teoria que pudesse ser contestada na intenção de eliminação de erro. Aplicando ao caso de projeto de espaço, as teorias existentes foram caracterizadas como os padrões de distribuição de espaço de trabalho, identificando-se a lacuna com a inexistência de formas de aplicação de dados específicos de realização de atividades. A nova teoria seria a forma de abordagem que levará a uma solução, e o confronto com a proposta seria a verificação da solução com a situação existente.

$\mathrm{Na}$ construção de um modelo teórico selecionou-se os fatores pertinentes ao estudo, tendo como hipótese a proposta de organização do espaço, definindo padrões dimensionais de atividades, a fim de verificar a utilização do espaço de trabalho. Os resultados encontrados nas observações representam as atividades realizadas no escritório (Diagrama 1).

Diagrama 1- Adequação das etapas à metodologia de configuração de espaço de trabalho

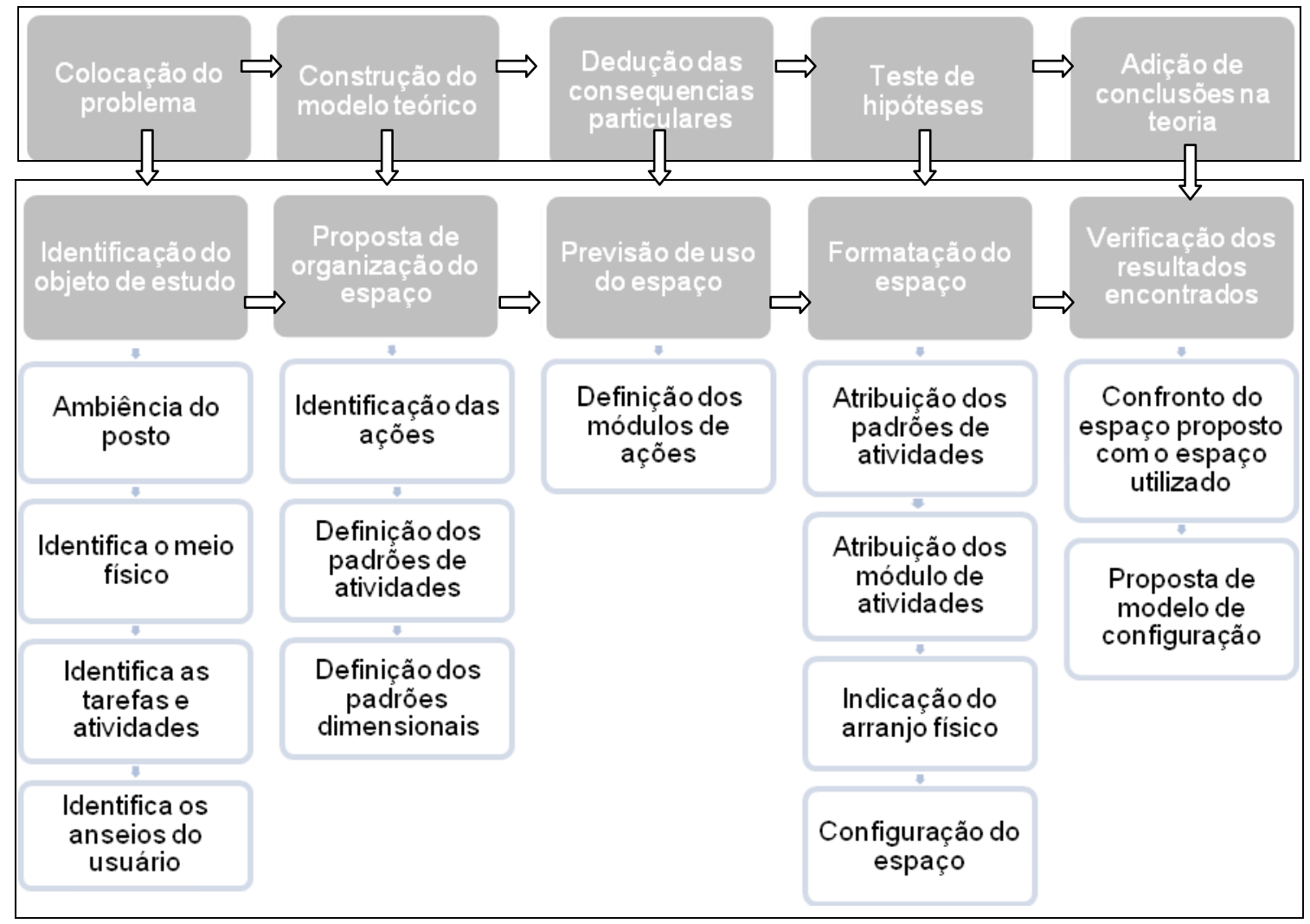

Fonte: autora. 2015

\subsection{Identificação do Objeto de Estudo}

Investigação das atividades, com ênfase na verificação da área ocupada na sua execução.

- Ambiência do posto de trabalho - conhecimento da unidade produtiva para compreender o funcionamento da empresa. 


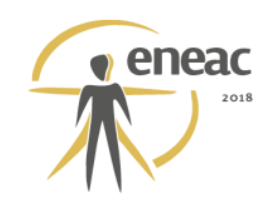

- Identificação do meio físico do posto de trabalho - relação das atividades com o espaço na identificação da tipologia de uso de espaço da empresa, para observar a distribuição interna do espaço físico e a correspondência à política administrativa da empresa.

- Análise do uso do espaço do posto de trabalho no plano horizontal entendimento do uso do espaço do posto de trabalho.

- Identificação das tarefas e atividades dos postos - relacionamento dos usuários às atividades realizadas e às funções designadas pela empresa. Além de colher informações com os próprios executores das atividades, utiliza-se a gravação de vídeo como meio de registro do momento efetivo da execução da atividade dessas atividades, através do programa iSEE (FILGUEIRAS, 2012).

- Na Identificação dos anseios do usuário aplica-se o "Poema dos Desejos", desenvolvida por Henry Sanoff (1991).

\subsection{Proposta de Organização do Espaço}

Definições de padrões de ações e padrões dimensionais, a partir dos dados do espaço físico e das ações realizadas nos ambientes de trabalho. A identificação das atividades que ocorrem de formas semelhantes constitui um padrão que sintetiza os acontecimentos no local e gera um conjunto de ações denominado "padrão de ação", representando as atividades realizadas no local. A definição de um padrão dimensional para executar as atividades aplica as relações antropométricas para conduzir a funcionalidade dos espaços, utilizando-se, como parâmetros dimensionais para o espaço de trabalho em escritório, as normas regulamentadoras e pesquisas científicas baseadas em princípios ergonômicos.

\subsection{Previsão de uso do Espaço}

Utilização de módulos de espaço para cada ação que acontece no espaço, baseada na análise e seleção realizadas na fase de definição de padrões dimensionais.

\subsection{Formatação do Espaço}

Identificação dos padrões correspondentes às atividades percebidas, aos quais são atribuídos módulos que passam a compor o posto de trabalho. A conjunção dos módulos leva à formatação do espaço físico do posto de trabalho.

\subsection{Verificação dos Resultados}

Confronto do modelo de posto de trabalho proposto com o objeto estudado, a fim de constatar a veracidade da solução proposta. O modelo proposto sintetiza as recomendações ergonômicas em um roteiro de configuração que direciona as etapas de investigação, travando uma relação entre os postos de trabalho existentes e as respectivas atividades.

\section{RESULTADOS}

A metodologia desenvolvida procurou aplicar os procedimentos de um método científico em um processo de configuração de um espaço de trabalho fundamentado em princípios ergonômicos. A linha mestra que conduziu o desenvolvimento da metodologia foi o projeto de um posto de trabalho em um ambiente físico, iniciando-se pelo conhecimento das características desejadas para o posto, a fim de fundamentar a sua formação, percorrendo as formas de quantificação de espaço e finalizando com a formatação do lugar. A 
elaboração de um Modelo de Configuração sintetizou os procedimentos adotados na metodologia, adaptando-os a um processo de configuração de postos de trabalho.

\section{REFERÊNCIAS BIBLIOGRÁFICAS}

ABNT Associação Brasileira de Normas Técnicas. http://www.abnt.org.br/abnt/ conheca-a-abnt. Acesso em 21/05/2015

BOUERI FILHO, José Jorge. Projeto e dimensionamento dos espaços da habitação - Espaços de atividades. E - book- Livro II, Estação das Letras e Cores, São Paulo. 2008

BRILL, M., MARGULIS, S. T., KONAR, E., \& BOSTI. Using office design to increase productivity. Workplace Design and Productivity, Inc. (Vol. 1 \& 2). Buffalo, NY. 1984

CHARLES, Kate E.; DANFORTH, Alison J.; VEITCH, Jennifer A.; ZWIERZCHOWSKI, Christina; JOHNSON, Byron; PERO, Karen. Workstation Design for Organizational Productivity. Practical advice based on scientific research findings for the design and management of open-plan offices. National Research Council of Canada and Public Works \& Government Services Canada. ISBN 0-662-38514-4. 2004. Disponível em: http://irc.nrc-cnrc.gc.ca/ie/productivity/index. Acessado em $01 / 04 / 2012$

CURY, Antonio. Organização e métodos: uma visão holística. $8^{a}$ edição. Editora Atlas. São Paulo. 2005

FILGUEIRAS, Ernesto Vilar. Desenvolvimento de um método para avaliação da interacção homem/cadeira de um escritório numa perspectiva sistémica e ecológica. Tese de Doutorado de Motricidade Humana na especialidade de Ergonomia da Universidade Técnica de Lisboa. 2012

HARRIS, David A.; PALMER, Alvin E.; LEWIS, M. Susan; MUNSON, David L.; MECKLER, Gershon; GERDES, Ralph. Planning and designing the office environment. Van Nostrand Reinhold Company. New York. 1981

IAB- Instituto de Arquitetos do Brasil. Anotações sobre o PROJETO em Arquitetura. Contribuição para a sua regulação profissional. Rio de Janeiro. 2013

MARCONI, Marina de Andrade; LAKATOS, Eva Maria. Fundamentos de Metodologia Científica. $6^{\mathbf{a}}$ Edição. Editora Atlas S. A. São Paulo. 2009

MARMOT, Alexi; ELEY, Joanna. Office Space Planning - Designing For Tomorrow's Workplace. McGraw-Hill, New York, 2000

MEEL, Juriaan van; MARTENS, Yuri; REE, Hermen Jan van. Planning Office Spaces- a pratical guide for managers and designers. Laurence King Publishing -London 2010

NEUFERT, Ernest. Neufert. Arte de projetar em arquitetura. 18 edição, Editora Gustavo Gili. Barcelona. 2013

PANERO, Juluis; ZELNIK, Martin. Dimensionamento humano para espaços interiores. 1를 Edição, 4ª impressão. Editorial Gustavo Gili, SL, Barcelona. 2008.

PILE, John. Open office space (the office book design series). Facts On File, Inc. NY. 1984

SANOFF, Henry. Visual Research Methods in Design. New York: Van Nostrand Reinhold, 1991 